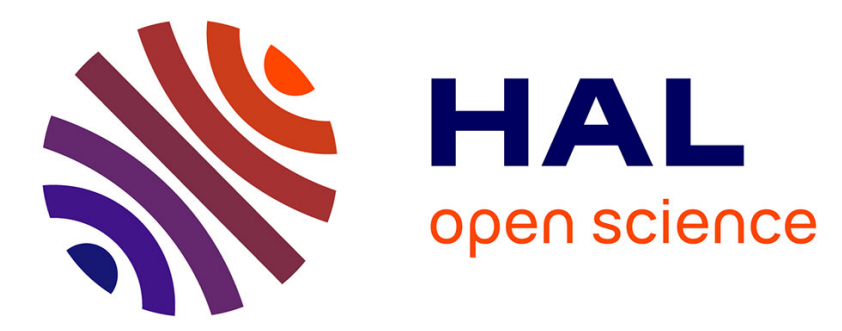

\title{
Structural determination of two new acacic acid-type saponins from the stem barks of Albizia zygia (DC.) J. F. Macbr
}

Olivier Placide Noté, Line Made Simo, Joséphine Ngo Mbing, Dominique Guillaume, Christian D. Muller, Dieudonné Emmanuel Pegnyemb, Annelise Lobstein

\section{To cite this version:}

Olivier Placide Noté, Line Made Simo, Joséphine Ngo Mbing, Dominique Guillaume, Christian D. Muller, et al.. Structural determination of two new acacic acid-type saponins from the stem barks of Albizia zygia (DC.) J. F. Macbr. Natural Product Research, 2018, 33 (2), pp.180-188. 10.1080/14786419.2018.1440228 . hal-02992576

\section{HAL Id: hal-02992576 https://hal.science/hal-02992576}

Submitted on 6 Nov 2020

HAL is a multi-disciplinary open access archive for the deposit and dissemination of scientific research documents, whether they are published or not. The documents may come from teaching and research institutions in France or abroad, or from public or private research centers.
L'archive ouverte pluridisciplinaire HAL, est destinée au dépôt et à la diffusion de documents scientifiques de niveau recherche, publiés ou non, émanant des établissements d'enseignement et de recherche français ou étrangers, des laboratoires publics ou privés. 


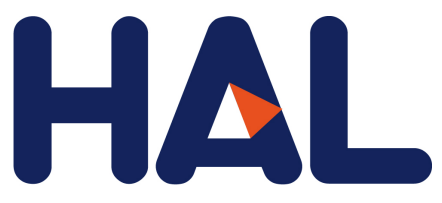

archives-ouvertes

\section{Structural determination of two new acacic acid-type saponins from the stem barks of Albizia zygia (DC.) J. F. Macbr}

Christian D. Muller, Olivier Noté, Line Simo, Joséphine Mbing, Dominique Guillaume, Christian Müller, Dieudonné Pegnyemb, Annelise Lobstein

\section{To cite this version:}

Christian D. Muller, Olivier Noté, Line Simo, Joséphine Mbing, Dominique Guillaume, et al.. Structural determination of two new acacic acid-type saponins from the stem barks of Albizia zygia (DC.) J. F. Macbr. Natural Product Research, Taylor \& Francis, 2018, 33, pp.180 - 188. 10.1080/14786419.2018.1440228 . hal-02992576

\section{HAL Id: hal-02992576 \\ https://hal.archives-ouvertes.fr/hal-02992576}

Submitted on 6 Nov 2020

HAL is a multi-disciplinary open access archive for the deposit and dissemination of scientific research documents, whether they are published or not. The documents may come from teaching and research institutions in France or abroad, or from public or private research centers.
L'archive ouverte pluridisciplinaire HAL, est destinée au dépôt et à la diffusion de documents scientifiques de niveau recherche, publiés ou non, émanant des établissements d'enseignement et de recherche français ou étrangers, des laboratoires publics ou privés. 


\title{
Structural determination of two new acacic acid-type saponins from the stem barks of Albizia zygia (DC.) J. F. Macbr
}

\author{
Olivier Placide Notéa,b, Line Made Simo ${ }^{a, b}$, Joséphine Ngo Mbing ${ }^{b}$, \\ Dominique Guillaumec, Christian Dominique Mullerd, \\ Dieudonné Emmanuel Pegnyemb ${ }^{b}$ and Annelise Lobstein ${ }^{\mathrm{a}}$
}

aFaculté de Pharmacie, Laboratoire d'Innovation Thérapeutique, UMR 7200, CNRS-Université de Strasbourg, Illkirch Cedex, France; 'baculté de Sciences, Laboratoire de Pharmacochimie des Substances Naturelles, Département de Chimie Organique, Université de Yaoundé I, Yaoundé, Cameroun; 'Laboratoire de Chimie Thérapeutique, UMR7312, Université de Reims, Reims, France; ${ }^{d}$ Institut Pluridisciplinaire Hubert Curien, UMR 7178 CNRS Université de Strasbourg, Illkirch Cedex, France

\begin{abstract}
As a continuation of our interest in the study of triterpenoid saponins from Albizia zygia, phytochemical investigation of its stem barks led to the isolation of two new oleanane-type saponins, named zygiaosides C-D (1-2). Their structures were established on the basis of extensive analysis of 1D and 2D NMR $(1 \mathrm{H}-, 13 \mathrm{C}$ NMR, DEPT, COSY, TOCSY, ROESY, HSQC and HMBC) experiments, HRESIMS studies, and by chemical evidence as, 3-O-[ $\beta$-D-glucopyranosyl-( $1 \rightarrow 2)-[\alpha-$ L-arabinopyranosyl-( $1 \rightarrow 6)]-\beta$-D-glucopyranosyl]-21-O-[(2E,6S)-2,6dimethyl-6-O-( $\beta$-D-quinovopyranosyl) octa-2,7-dienoyl]acacic acid $28-O-\alpha$-L-arabinofuranosyl-( $1 \rightarrow 4)$-[ $\beta$-D-glucopyranosyl- $(1 \rightarrow 3)]-\alpha$-Lrhamnopyranosyl-(1 $\rightarrow 2)-\beta$-D-glucopyranosyl ester (1) and 3-O-[ $\beta$-Dglucopyranosyl-( $1 \rightarrow 2)$-[ $\beta$-D-fucopyranosyl-( $1 \rightarrow 6)]-\beta$-D-glucopyranosyl]21-O-[(2E,6S)-2,6-dimethyl-6-O-( $\beta$-D -quinovopyranosyl) octa-2,7-dienoyl]acacic acid 28-O- $\alpha$-L-arabinofuranosyl-( $1 \rightarrow 4)$-[ $\beta$-Dglucopyranosyl-( $1 \rightarrow 3)]$ - $\alpha$-L-rhamnopyranosyl-( $1 \rightarrow 2)-\beta$-D-glucopyranosyl ester (2).
\end{abstract}

\section{ARTICLE HISTORY}

Received 15 January 2018

Accepted 7 February 2018

\section{KEYWORDS}

1D and 2D NMR; Albizia zygia; mimosaceae; triterpenoid saponins; acacic acid-type saponins

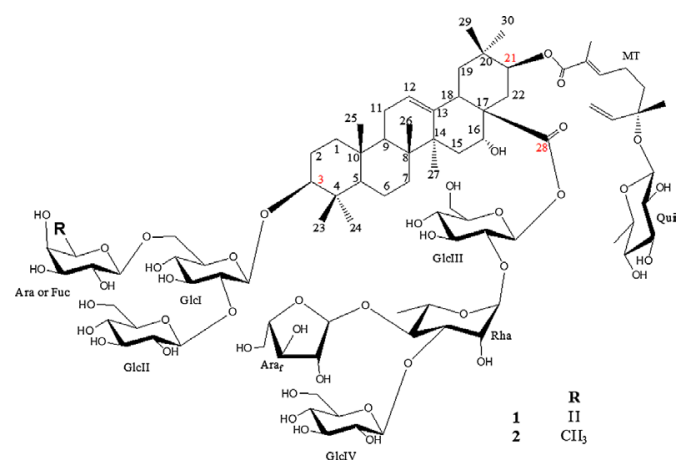

CONTACT Olivier Placide Noté oliviernote1@yahoo.fr

(4) Supplemental data for this article can be accessed at https://doi.org/10.1080/14786419.2018.1440228 


\section{Introduction}

The genus Albizia comprises about 150 species widely distributed in the tropics, with the greatest diversity in Africa and South America (Abdel-Kader et al. 2001). Triterpenoid saponins, mainly described in this genus are complex acacic acid glycosides, sharing the same structural features: they all have acacic acid as aglycon unit, oligosaccharide moieties at C-3 and C-28, and an acyl group at C-21. Recently, adianthifoliosides (Haddad et al. 2003, 2004), grandibracteosides (Krief et al. 2005), gummiferaosides (Cao et al. 2007), julibrosides (Liang et al. 2005; Zheng et al. 2006, 2010; Zou et al. 2010), coriariosides (Noté et al. 2009, 2010); albizosides (Liu et al. 2010), and lebbeckosides (Noté et al. 2015) have been reported.

In our previous work, we described the isolation of two acacic acid glycosides, new apoptosis-inducing agents, named zygiaosides A-B from the $n$-BuOH extract of the roots of Albizia zygia (DC.) J.F. Macbr (Noté et al. 2016). As part of our continuing study of triterpenoid saponins from this plant, investigation of its stem barks resulted in the isolation of two new acacic acid-type saponins, named zygiaosides C-D (1-2). Herein, we report their isolation and structural determination.

\section{Results and discussion}

The air-dried finely powdered stem bark of A. zygia was extracted with $\mathrm{EtOH} 70 \%$ in a Soxhlet apparatus. After evaporation of the solvent, the resulting brown residue was suspended in $70 \mathrm{~mL}$ of water and then submitted to column chromatography (CC) using Diaion HP-20 resin yielding four main fractions after TLC monitoring. The crude saponin mixture was then submitted to VLC using silica gel to give five main subfractions. Purification of the eluated subfractions by Semprep-HPLC afforded two new triterpenoid saponins, named zygiaosides C-D (1-2) (Figure 1).

Zygiaoside C (1) was obtained as a white, amorphous powder. Its high-resolution electrospray ionization mass spectrometry (HRESIMS) (positive-ion mode) exhibited a pseudo-molecular ion peak at $\mathrm{m} / \mathrm{z} 1877.8960\left[\mathrm{M}+\mathrm{NH}_{4}\right]^{+}(\mathrm{calcd} 1877.8956)$, consistent with a molecular formula of $\mathrm{C}_{86} \mathrm{H}_{138} \mathrm{O}_{43}$. Upon acid hydrolysis with $2.0 \mathrm{M} \mathrm{HCl}, 1$ gave an acacic acid lactone unit, which was identified with an authentic sample, together with glucose (Glc), arabinose (Ara), rhamnose (Rha), arabinofuranose ( (ra $_{\mathrm{f}}$ ), and quinovose (Qui), which were identified by co-TLC with authentic samples. The absolute configuration of these sugar res-

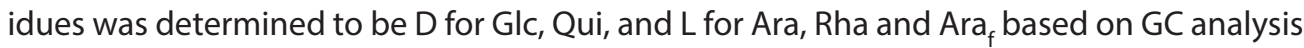
of their trimethylsilyl thiazolidine derivatives (See Experimental Section) (Chaabi et al. 2010). ${ }^{1} \mathrm{H}$ NMR spectrum of 1 showed seven angular methyl groups as singlets at $\delta_{H} 0.97,1.07,1.10$, $1.16,1.19,1.23$, and 1.84 (each $3 \mathrm{H}, \mathrm{s})$, one olefinic proton at $\delta_{\mathrm{H}} 5.65(\mathrm{H}-12)$, one oxygen-bearing methine proton at $\delta_{\mathrm{H}} 3.24(\mathrm{H}-3)$, and sugar proton signals between $\delta_{\mathrm{H}} 3.74-6.30$. Its ${ }^{13} \mathrm{C}$ NMR spectrum showed two olefinic carbon signals at $\delta_{C} 123.0$ and 143.3 , suggesting that 1 was an oleanane type triterpenoid saponin. $1 \mathrm{D}\left({ }^{1} \mathrm{H}\right.$ and ${ }^{13} \mathrm{C}$ NMR, DEPT) and 2D (COSY, HSQC and $\mathrm{HMBC}$ ) NMR techniques permitted the unambiguous assignment of all ${ }^{1} \mathrm{H}$ and ${ }^{13} \mathrm{C}$ NMR signals of the aglycon of 1 identified as acacic acid $(3 \beta, 16 \alpha, 21 \beta$-trihydroxyolean-12-ene-28-oic acid) by comparison of its ${ }^{1} \mathrm{H}$ and ${ }^{13} \mathrm{C}$ NMR signals with those reported in the literature (Table S1) (Noté et al. 2015, 2016).

Substitutions at C-3 and C-28 of acacic acid were evidenced by the observed glycosylation-induced shifts of C-3 at $\delta_{C} 89.1$ (deshielded signal for C-3 of the aglycon) and C-28 at 


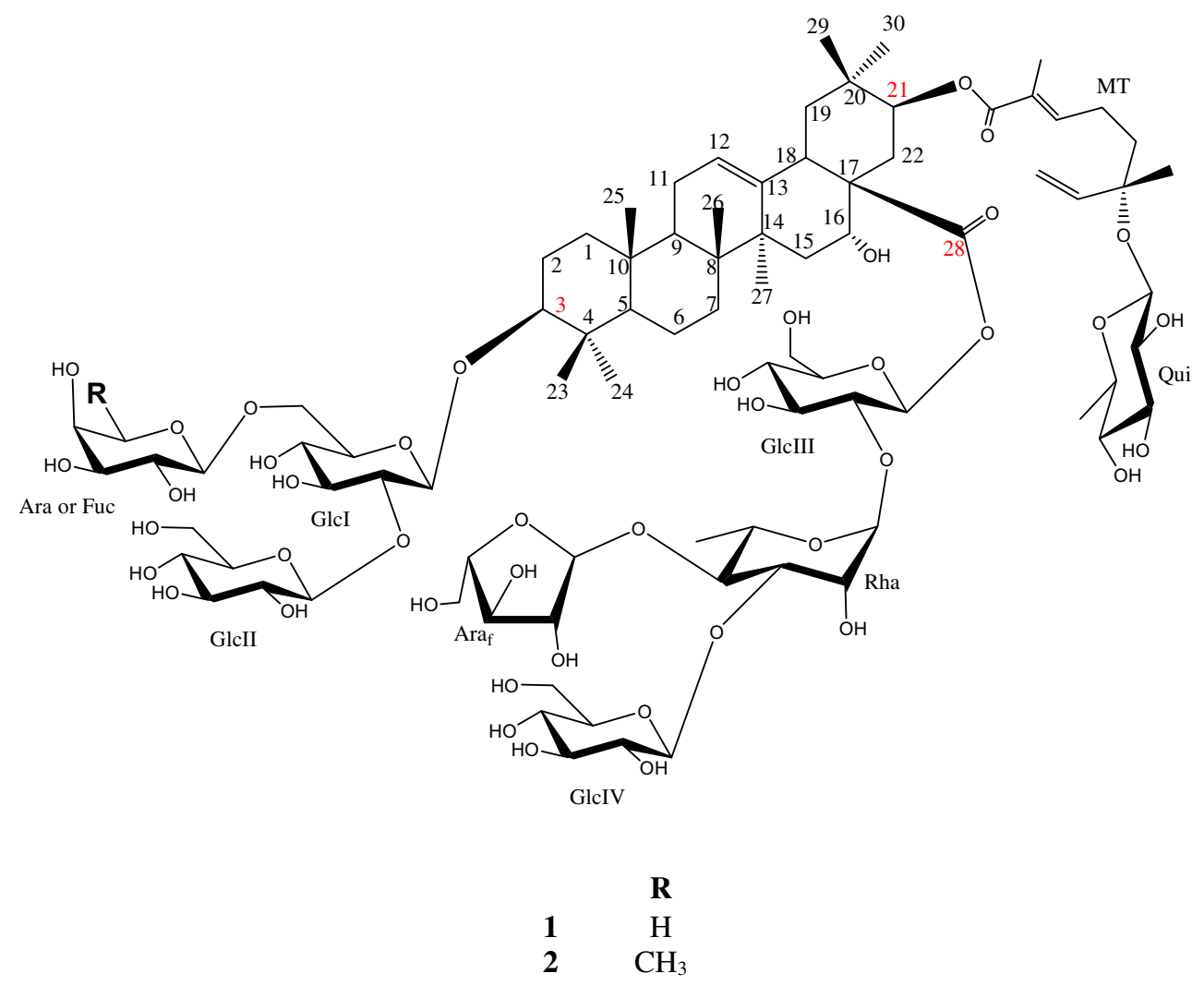

Figure 1. Structure of isolated saponins (1-2).

$\delta_{C} 174.4$ (shielded signal for $\mathrm{C}-28$ of the aglycon). Substitution at C-21 was ascertained from the acylation-induced shift observed for C-21 at $\delta_{C} 76.9$ (deshielded signal for C-21 of the aglycon). All of these data established that 1 was a 21-acyl 3, 28-bidesmosidic acacic acid derivative, sugar chains being linked to C -3 and C-28 through an ether and ester bond, respectively.

Concerning the sugar units, the ${ }^{1} \mathrm{H}$ NMR spectrum of 1 showed eight anomeric protons at $\delta_{\mathrm{H}} 4.84(1 \mathrm{H}, \mathrm{d}, J=7.3 \mathrm{~Hz}), 4.94(1 \mathrm{H}, \mathrm{d}, J=6.8 \mathrm{~Hz}), 5.35(1 \mathrm{H}, \mathrm{d}, J=7.3 \mathrm{~Hz}), 6.10(1 \mathrm{H}, \mathrm{d}$, $J=8.2 \mathrm{~Hz}), 5.93(1 \mathrm{H}, \mathrm{brs}), 6.29(1 \mathrm{H}, \mathrm{brs}), 5.36(1 \mathrm{H}, \mathrm{d}, J=7.8 \mathrm{~Hz})$, and $4.90(1 \mathrm{H}, \mathrm{d}, J=7.8 \mathrm{~Hz})$ which gave correlations in the HSQC spectrum with carbon atom resonances at $\delta_{C} 104.9$, 105.3, 105.7, 95.6, 101.8, 111.0, 105.9 and 99.3, respectively (Tables S2 and S3). The ${ }^{1} \mathrm{H}$ and ${ }^{13} \mathrm{C}$ NMR data (Tables S2-S3) of the monosaccharide residues were assigned starting, either from the readily identifiable anomeric proton of each hexosyl or pentosyl unit, or from the $\mathrm{CH}_{3}$-proton doublet of each 6-deoxyhexosyl unit, by means of COSY, HSQC-TOCSY, HSQC, NOESY, and HMBC spectra obtained for this compound. Based on the coupling constants of the anomeric protons and the chemical shifts of the anomeric carbons, the anomeric configuration of the sugar moieties were determined as $\beta$ for the glucose and quinovose moieties and $\alpha$ for arabinose, rhamnose and arabinofuranose moieties.

In addition, the ${ }^{1} \mathrm{H}$ NMR spectrum of compound 1 exhibited one olefinic proton signal at $\delta_{H} 6.94(1 \mathrm{H}, \mathrm{t}, J=7.2 \mathrm{~Hz})$, and one group of one-substituted olefinic proton signals at $\delta_{H} 6.21$ 
$(1 \mathrm{H}, \mathrm{dd}, J=10.2 ; 17.8 \mathrm{~Hz}), 5.25(1 \mathrm{H}, \mathrm{d}, J=10.2 \mathrm{~Hz})$ and $5.46(1 \mathrm{H}, \mathrm{d}, J=17.8 \mathrm{~Hz})$, indicating that compound 1 has one monoterpenoid unit (Table S3) (Liu et al. 2010).

The sequencing of the glycosidic chains was achieved by analysis of HMBC and NOESY experiments. For the oligosaccharide moiety at $\mathrm{C}-3$, connectivity observed in the HMBC spectrum between $\delta_{\mathrm{H}} 4.84(\mathrm{H}-1 \mathrm{Glcl})$ and $\delta_{\mathrm{C}} 89.1$ (C-3 Agly), suggested that this sugar was directly attached to $\mathrm{C}-3$ of the aglycon. This was supported by the NOESY correlation observed between $\delta_{\mathrm{H}} 4.84(\mathrm{H}-1 \mathrm{Glcl})$ and $\delta_{\mathrm{H}} 3.24(\mathrm{H}-3 \mathrm{Agly})$. The HMBC correlation observed between $\delta_{\mathrm{H}} 4.94(\mathrm{H}-1 \mathrm{Ara})$ and $\delta_{\mathrm{C}} 69.7(\mathrm{C}-6 \mathrm{Glcl})$, allowed us to suggest that Ara was linked to $\mathrm{C}-6$ of Glcl. This was supported by the NOESY correlation observed between $\delta_{H} 4.94(\mathrm{H}-1$ Ara) and $\delta_{\mathrm{H}} 4.26(\mathrm{H}-6 \mathrm{a} \mathrm{Gl} \mathrm{cl})$. Moreover, in the $\mathrm{HMBC}$ spectrum, a correlation observed between $\delta_{\mathrm{H}} 5.35(\mathrm{H}-1 \mathrm{Glcll})$ and $\delta_{\mathrm{C}} 83.0(\mathrm{C}-2 \mathrm{Glcl})$, indicated that $\mathrm{Glcll}$ was linked at $\mathrm{C}-2$ of Glcl. This was confirmed by the NOESY correlation observed between $\delta_{H} 5.35(\mathrm{H}-1 \mathrm{Glcll})$ and $\delta_{\mathrm{H}} 4.18(\mathrm{H}-2 \mathrm{Glcl})$ (Figure 2a). These data are consistent with a triglycosidic chain determined as $\beta$-D-glucopyranosyl-( $1 \rightarrow 2)$-[ $\alpha$-L-arabinopyranosyl-( $1 \rightarrow 6)]-\beta$-D-glucopyranosyl unit linked to $\mathrm{C}-3$ of the aglycon.

In addition, extensive analysis of 1D and 2D NMR spectra of 1, revealed the sugar moiety at C-28 was identical to that of julibrosides $J_{16}$ and $J_{17}$ (Zou et al. 2010), $J_{14}$ and $J_{28}$ (Liang et al. 2005), $J_{32} J_{35^{\prime}}$ and $J_{36}$ (Zheng et al. 2006), adianthifoliosides A-F (Haddad et al. 2003, 2004), and coriarioside A (Noté et al. 2009), and the monoterpene-quinovosyl moiety at C-21 was identical to that of adianthifolioside $\mathrm{F}$ (Haddad et al. 2004) and prosapogenin-8 (Zheng et al. 2006). Hence, the units attached at C-28 and C-21 of the aglycon of 1 were established as $\alpha$-L-arabinofuranosyl-( $1 \rightarrow 4)$-[ $\beta$-D-glucopyranosyl-( $1 \rightarrow 3)$ ]- $\alpha$-L-rhamnopyranosyl-( $1 \rightarrow 2)-\beta$-D-glucopyranoside, and (2E,6S)-2,6-dimethyl-6-O-( $\beta$-D-quinovopyranosyl)octa-2,7-dienoyl, respectively (Figure $2 \mathrm{~b}$ and $\mathrm{c}$ ). Consequently, the structure of zygiaosides $C(\mathbf{1})$ was determined as 3-O-[ $\beta$-D-glucopyranosyl-(1 $\rightarrow 2)$-[ $\alpha$-L-arabinopyranosyl-(1 $\rightarrow 6)]-\beta$-D-glucopyranosyl]-21-O[(2E,6S)-2,6-dimethyl-6-O-( $\beta$-D-quinovopyranosyl)octa-2,7-dienoyl] acacic acid 28-O- $\alpha$-Larabinofuranosyl-( $1 \rightarrow 4)$-[ $\beta$-D-glucopyranosyl-( $1 \rightarrow 3)$ ]- $\alpha$-L-rhamnopyranosyl-( $1 \rightarrow 2)-\beta$-Dglucopyranosyl ester, a new acacic acid-type saponin.

Compound 2, obtained as a white amorphous powder, exhibited in its HRESIMS spectrum (positive-ion mode) a pseudo-molecular ion peak at $\mathrm{m} / \mathrm{z} 1895.8614[\mathrm{M}+\mathrm{Na}]^{+}$(calcd 1895.8661), consistent with a molecular formula of $\mathrm{C}_{87} \mathrm{H}_{140} \mathrm{O}_{43}$. As already observed for $\mathbf{1}$, acid hydrolysis of $\mathbf{2}$ also afforded an acacic acid lactone unit, identified by co-TLC with authentic sample, together with D-glucose, D-fucose, D-quinovose, L-arabinofuranose and L-rhamnose units which were identified by GC analysis of their trimethylsilyl thiazolidine derivatives (See Experimental Section). Comparison of 1D and 2D NMR data of $\mathbf{2}$ with those of $\mathbf{1}$ indicated that 2 had also acacic acid as aglycon (Table S1). The observation of glycosylation- and acylation-induced shifts at $\delta_{\mathrm{C}} 89.2$ (C-3 Agly), 76.8 (C-21 Agly), and 174.4 (C-28 Agly) in the ${ }^{13} \mathrm{C}$ NMR spectrum of 2 suggested that it should be also a 21-acyl 3,28-bidesmosidic acacic acid derivative with sugar chains linked to C-3 and C-28 through an ether and ester bond, respectively, and with an acyl group attached at C-21. The ${ }^{1} \mathrm{H}$ NMR spectrum of 2 showed eight anomeric protons signals at $\delta_{\mathrm{H}} 4.83[1 \mathrm{H}, \mathrm{d}, J=7.4 \mathrm{~Hz}$, glucose $(\mathrm{Glcl})], 4.90[1 \mathrm{H}, \mathrm{d}$, $J=7.8 \mathrm{~Hz}$, fucose (Fuc)], $5.35[1 \mathrm{H}, \mathrm{d}, J=7.8 \mathrm{~Hz}$, glucose $(\mathrm{Glcll})], 6.09[1 \mathrm{H}, \mathrm{d}, J=7.9 \mathrm{~Hz}$, glucose (Glclll)], $5.93[1 \mathrm{H}$, brs, rhamnose (Rha)], $5.37[1 \mathrm{H}, \mathrm{d}, J=7.7 \mathrm{~Hz}$, glucose (GlclV)], 6.30 [1H, brs, arabinofuranose (Araf)], and $4.89[1 \mathrm{H}, \mathrm{d}, J=7.8 \mathrm{~Hz}$, quinovose (Qui)], which correlated with eight anomeric carbon atom resonances at $\delta_{C} 105.0,105.5,105.7,95.7,101.8,105.9,111.0$, and 99.3, respectively in the HSQC spectrum (Tables S2 and S3). Comparison of the NMR data 


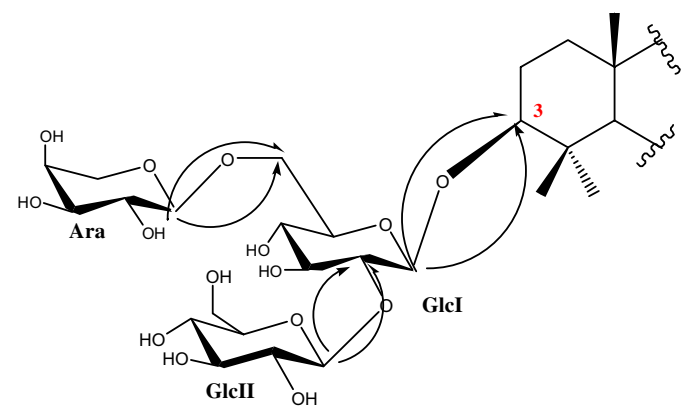

(a)

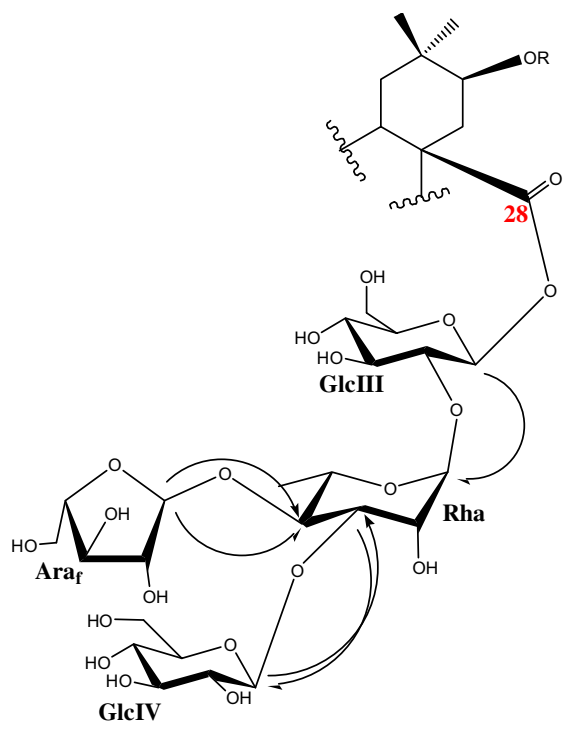

(b)

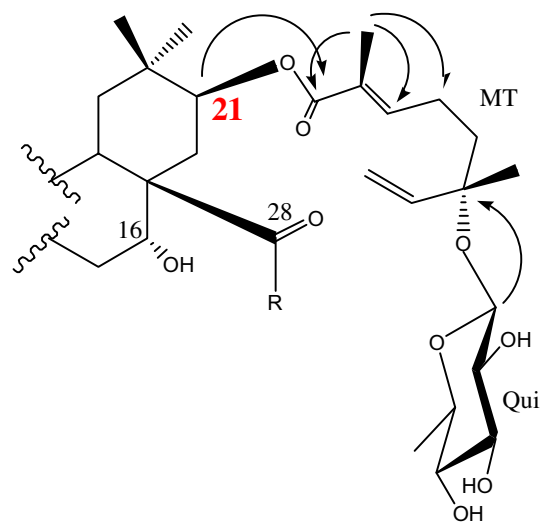

(c)

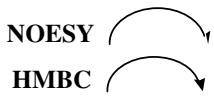

Figure 2. Key HMBC and NOESY correlations of compound 1.

of $\mathbf{2}$ with those of $\mathbf{1}$ revealed that the units attached at C-21 and C-28 of the aglycon of $\mathbf{2}$ were identical to those of $\mathbf{1}$. Therefore, the units attached at C-21 and C-28 of $\mathbf{2}$ were established as [(2E,6S)-2,6-dimethyl-6-O-( $\beta$-D-quinovopyranosyl)octa-2,7-dienoyl]and $\alpha$-L-arabinofuranosyl$(1 \rightarrow 4)$-[ $\beta$-D-glucopyranosyl-( $1 \rightarrow 3)]-\alpha$-L-rhamnopyranosyl-( $1 \rightarrow 2)$ - $\beta$-D-glucopyranoside moiety, respectively. However, the oligosaccharide chain at C-3 in $\mathbf{2}$ was similar to those of $\mathbf{1}$ except for the appearance of fucopyranosyl signals instead of arabinopyranosyl signals observed in 1. Extensive analysis of $1 D$ and $2 D$ NMR spectra of 2 allowed us to identify the unit attached at C-3 as $\beta$-D-glucopyranosyl-(1 $\rightarrow 2)$-[ $\beta$-D-fucopyranosyl-( $1 \rightarrow 6)]-\beta$-D-glucopyranoside, a unit identical to that of gummiferaoside $C$ obtained from Albizia gummifera (Cao et al. 2007). Thus, the structure of compound 2 was established as $3-O-[\beta-D-g l u c o p y r a n o s y l-(1 \rightarrow 2)$ 
-[ $\beta$-D-fucopyranosyl-(1 $\rightarrow 6)]-\beta$-D-glucopyranosyl]-21-O-[(2E,6S)-2,6-dimethyl-6-O-( $\beta$-D-quinovopyranosyl)octa-2,7-dienoyl]acacicacid28-O- $\alpha$-L-arabinofuranosyl-(1 $\rightarrow 4)$-[ $\beta$-D-glucopyranosyl$(1 \rightarrow 3)$ ]- $\alpha$-L-rhamnopyranosyl-(1 $\rightarrow 2)-\beta$-D-glucopyranosyl ester, a new acacic acid-type saponin, named zygiaoside $D$.

\section{Experimental}

\subsection{General experimental procedure}

Optical rotations were measured on a Jasco P-2000 polarimeter. ${ }^{1} \mathrm{H}$ NMR $(600 \mathrm{MHz})$ and ${ }^{13} \mathrm{C}$ NMR $(150 \mathrm{MHz})$ spectra were recorded at room temperature in pyridine- $d_{5}$ using a Bruker $600 \mathrm{MHz}$ spectrometer. Chemical shifts are given in $\delta(\mathrm{ppm})$ value relative to TMS as internal standard. HRESIMS spectra were recorded on a microTOF ESI-TOF mass spectrometer (Agilent) operating in positive mode. Analytical HPLC was performed on Varian 920-LC apparatus equipped with an autosampler, a pump, a diode array detector (DAD), and Galaxie software. Semipreparative HPLC was performed on a Gilson apparatus equipped with Trilution LC software using a Nucleodur 100-5 C18ec $(21 \times 250 \mathrm{~mm}, 5 \mu \mathrm{m})$ column purchased from Machery-Nagel (Germany). Thin layer chromatography (TLC) was performed on precoated silica gel plates $\left(60 \mathrm{~F}_{254^{\prime}}\right.$ Merck) using the system solvent $n$ - $\mathrm{BuOH}-\mathrm{AcOH}-\mathrm{H}_{2} \mathrm{O}, 65: 15: 25$ as eluent. The spots were observed after spray with Komarowsky reagent, which is a mixture (5:1) of para-hydroxybenzaldehyde (2\% in $\mathrm{MeOH}$ ) and Ethanolic $\mathrm{H}_{2} \mathrm{SO}_{4}$ (50\%). Column chromatography (CC) was carried out using Diaion HP-20 resin, and Vacuum-liquid chromatography (VLC) using silica gel 60 (15-40 and 40-63 $\mu \mathrm{m}$ ).

\subsection{Plant material}

The stem barks of $A$. zygia were harvested at Nkolbisson, Yaoundé peripheral quarter, in Cameroon in November 2013 under the guidance of Mr. Victor Nana, botanist of the National Herbarium of Cameroon (NHC), where a voucher specimen (2339/SRFK) was deposited.

\subsection{Extraction and isolation}

Air-dried finely powdered stem barks ( $100 \mathrm{~g}$ ) of A. zygia were extracted with EtOH $70 \%$ in a Soxhlet apparatus. This hydroalcoholic solution was then evaporated to dryness under reduced pressure to give a dark residue $(8.0 \mathrm{~g})$. This residue was suspended in $70 \mathrm{~mL}$ of water and then submitted to column chromatography (CC) using Diaion HP-20 resin, eluting with $\mathrm{H}_{2} \mathrm{O}, 50 \% \mathrm{MeOH}, 70 \% \mathrm{MeOH}, 80 \% \mathrm{MeOH}, 90 \% \mathrm{MeOH}$, and $100 \% \mathrm{MeOH}$, successively giving four main fractions (ZE1-ZE4) after TLC monitoring. The $80 \% \mathrm{MeOH}$ fraction (ZE3) was evaporated to dryness yielding a crude saponin mixture $(1.449 \mathrm{~g})$ that was then submitted to VLC using silica gel $60(15-40 \mu \mathrm{m})$, eluted with $\mathrm{CH}_{2} \mathrm{Cl}_{2}-\mathrm{MeOH}(80: 20)$ and $\mathrm{CH}_{2} \mathrm{Cl}_{2}-\mathrm{MeOH}-\mathrm{H}_{2} \mathrm{O}$ (70:30:5, 60:32:6.5) to give five main subfractions (ZE31-ZE35). Subfraction ZE35 (255.6 mg) was purified by semipreparative HPLC using gradient system of $\mathrm{CH}_{3} \mathrm{CN}-\mathrm{H}_{2} \mathrm{O}(20 \mathrm{~mL} / \mathrm{min})$ to yield compounds 1 ( $t_{\mathrm{R}^{\prime}} 5.30 \mathrm{~min}, 7.3 \mathrm{mg}$ ) and $\mathbf{2}\left(t_{\mathrm{R}^{\prime}} 5.90 \mathrm{~min}, 8.0 \mathrm{mg}\right)$. 


\subsection{Acid hydrolysis and GC Analysis}

Each saponin ( $2 \mathrm{mg}$ ) was hydrolyzed with $2 \mathrm{~mL}$ of $2 \mathrm{M} \mathrm{HCl}$ at $85^{\circ} \mathrm{C}$ during $2 \mathrm{~h}$. After cooling, the solvent was removed under reduced pressure. The sugar mixture was extracted from the aqueous phase $(10 \mathrm{~mL})$ and washed with $\mathrm{CH}_{2} \mathrm{Cl}_{2}(3 \times 5 \mathrm{~mL})$. Combined $\mathrm{CH}_{2} \mathrm{Cl}_{2}$ extracts were washed with water to give after evaporation the aglycon moiety, which was compared with authentic standard sample by Co-TLC. The sugars were first analyzed by TLC over silica gel $\left(\mathrm{CHCl}_{3}-\mathrm{MeOH}-\mathrm{H}_{2} \mathrm{O}, 8: 5: 1\right)$ by comparison with standard samples. The absolute configuration of each monosaccharide was determined from GC-MS analysis of their trimethylsilylated derivatives by comparison with authentic samples using the method previously described (Chaabi et al. 2010). The following sugars were detected: D-glucose, D-fucose, D-quinovose, L-arabinose, L-arabinofuranose and L-rhamnose.

\subsubsection{Zygiaoside C (1)}

Amorphous white powder; $[\alpha]_{D}^{25}-17(c=0.10, \mathrm{MeOH})$; HRESIMS (positive ion mode) $\mathrm{m} / \mathrm{z}$ $1877.8960\left(\left[\mathrm{M}+\mathrm{NH}_{4}\right]^{+}\right.$calcd for $\mathrm{C}_{86} \mathrm{H}_{142} \mathrm{O}_{43} \mathrm{~N}$ 1877.8956); ${ }^{1} \mathrm{H} /{ }^{13} \mathrm{C}$ NMR (The ${ }^{1} \mathrm{H}$ NMR data of 1 was measured at $600 \mathrm{MHz}$ and the ${ }^{13} \mathrm{C}$ NMR spectra at $150 \mathrm{MHz}$ in pyridine- $\mathrm{d}_{5}$. Ordered in the No. of 1): Aglycon: $\delta 1.60,1.03 / 38.7 ; 2.37,1.92 / 26.7 ; 3.24 / 89.1 ;-/ 39.5 ; 074 / 55.8 ; 1.66 / 18.6$; 1.71, 1.63/33.5;-/40.4; 1.78/47.0;-/36.9; 2.46, 2.03/23.7; 5.65 (1H, br s)/123.0;-/143.3;-/42.0; $2.28,2.05 / 35.9 ; 5.26 / 73.8 ;-/ 51.6 ; 3.48 / 41.0 ; 3.02,1.50 / 48.0 ;-/ 35.3 ; 6.26 / 76.9 ; 2.18,2.78 / 36.3$; $1.23(3 \mathrm{H}, \mathrm{s}) / 28.1 ; 1.16(3 \mathrm{H}, \mathrm{s}) / 16.6 ; 0.97(3 \mathrm{H}, \mathrm{s}) / 15.8 ; 1.19(3 \mathrm{H}, \mathrm{s}) / 17.2 ; 1.84(3 \mathrm{H}, \mathrm{s}) / 27.2 ;-/ 174.4 ;$ $1.07(3 \mathrm{H}, \mathrm{s}) / 29.1 ; 1.10(3 \mathrm{H}, \mathrm{s}) / 19.1$. MT: $\delta-/ 167.6 ;-/ 129.3 ; 6.94(1 \mathrm{H}, \mathrm{t}, 7.2) / 142.4 ; 2.45 / 23.6$; 1.78/40.4; $-/ 80.4 ; 6.21(1 \mathrm{H}, \mathrm{dd}, 10.2,17.8) / 144.1 ; 5.25(1 \mathrm{H}, \mathrm{d}, 10.2), 5.46(1 \mathrm{H}, \mathrm{d}, 17.8) / 114.8$; $1.87(3 \mathrm{H}, \mathrm{s}) / 12.7 ; 1.57(3 \mathrm{H}, \mathrm{s}) / 23.6 . \mathrm{Glc} l: \delta 4.84(1 \mathrm{H}, \mathrm{d}, 7.3) / 104.9 ; 4.18 / 83.0 ; 4.14 / 78.3 ; 4.05 / 71.1$; 4.06/76.4; 4.26, 4.85/69.7. GIc II: $\delta 5.35(1 \mathrm{H}, \mathrm{d}, 7.3) / 105.7 ; 4.02 / 75.4 ; 4.14 / 77.3 ; 3.83 / 71.0$; 3.73/77.0; 4.24, 4.50/62.7. Ara : $\delta 4.94(1 \mathrm{H}, \mathrm{d}, 6.8) / 105.3 ; 4.47 / 72.2 ; 4.19 / 74.4 ; 4.35 / 69.1 ; 3.78$, 4.32/66.4. Qui : $\delta$ 4.90/99.3; 4.02/75.5; 4.14/76.3; 3.75/76.8; 3.73/72.6; $1.62(3 \mathrm{H}, \mathrm{d}, 6.3) / 18.9$. Glc III: $\delta 6.10$ (1H, d, 8.2)/95.6; 4.02/76.0; 4.16/78.2; 4.13/71.4; 3.97/79.1; 4.16, 4.46/62.4. Rha: $\delta 5.93(1 \mathrm{H}$, br s)/101.8; 5.19/70.6; 4.96/81.9; 4.52/79.1; 4.57/69.0; 1.81 (3H, d, 6.3)/18.9. GIc IV: $\delta 5.36(1 \mathrm{H}, \mathrm{d}, 7.8) / 105.9 ; 3.99 / 75.1 ; 4.14 / 77.3 ; 4.12 / 71.1 ; 3.92 / 78.2 ; 4.17,4.28 / 62.7$. Araf $: \delta$ $6.29(1 \mathrm{H}$, br s)/111.0; 5.02/84.5; 4.83/78.1; 4.77/85.4; 3.78, 4.31/61.8. (Overlapped proton NMR signals are reported without designated multiplicity).

\subsubsection{Zygiaoside $D(2)$}

Amorphous powder; $[\alpha]_{D}^{25}+22(c=0.15, \mathrm{MeOH}) ; \mathrm{HRESIMS}$ (positive ion mode) $\mathrm{m} / \mathrm{z} 1895.8614$ $\left([\mathrm{M}+\mathrm{Na}]^{+}\right.$calcd for $\left.\mathrm{C}_{87} \mathrm{H}_{140} \mathrm{O}_{43} \mathrm{Na} 1895.8661\right) ;{ }^{1} \mathrm{H} /{ }^{13} \mathrm{C}$ NMR (The ${ }^{1} \mathrm{H}$ NMR data of 2 was measured at $600 \mathrm{MHz}$ and the ${ }^{13} \mathrm{C}$ NMR spectra at $150 \mathrm{MHz}$ in pyridine- $\mathrm{d}_{5}$. Ordered in the No. of 2): Aglycon: $\delta$ 1.61, 1.06/38.8; 2.41, 1.93/26.7; 3.22/89.2; -/39.5; 0.73/55.9; 1.65, 1.49/18.6; $1.71,1.64 / 33.4 ;-/ 40.4 ; 1.79 / 47.0 ;-/ 36.9 ; 2.46,2.04 / 23.8 ; 5.66(1 \mathrm{H}, \mathrm{br} \mathrm{s}) / 123.0 ;-/ 143.2 ;-/ 42.0$; 2.27, 2.03/35.9; 5.25/73.7;-/51.6; 3.49/41.0; 3.02, 1.49/48.0;-/35.2; 6.26/76.8; 2.19, 2.79/36.3; $1.22(3 \mathrm{H}, \mathrm{s}) / 28.1 ; 1.16(3 \mathrm{H}, \mathrm{s}) / 16.5 ; 0.98(3 \mathrm{H}, \mathrm{s}) / 15.8 ; 1.19(3 \mathrm{H}, \mathrm{s}) / 17.2 ; 1.84(3 \mathrm{H}, \mathrm{s}) / 27.1 ;-/ 174.4 ;$ $1.07(3 \mathrm{H}, \mathrm{s}) / 29.1 ; 1.10(3 \mathrm{H}, \mathrm{s}) / 19.2$. MT: $\delta-/ 167.6 ;-/ 129.7 ; 6.94(1 \mathrm{H}, \mathrm{t}, 7.3) / 142.4 ; 2.46 / 23.6$; 1.78/40.4; $-/ 80.4 ; 6.21(1 \mathrm{H}, \mathrm{dd}, 10.2,17.8) / 144.1 ; 5.24(1 \mathrm{H}, \mathrm{d}, 10.2), 5.46(1 \mathrm{H}, \mathrm{d}, 17.8) / 114.8$; $1.87(3 \mathrm{H}, \mathrm{s}) / 12.7 ; 1.57(3 \mathrm{H}, \mathrm{s}) / 23.6 . \mathrm{Glc}$ l: $\delta 4.83(1 \mathrm{H}, \mathrm{d}, 7.4) / 105.0 ; 4.18 / 83.0 ; 4.14 / 78.3 ; 4.06 / 71.1$; 4.07/76.4; 4.26, 4.91/70.0. Glc II: $\delta 5.35(1 \mathrm{H}, \mathrm{d}, 7.8) / 105.7 ; 4.02 / 75.3 ; 4.14 / 77.3 ; 3.84 / 71.0$; 3.74/77.0; 4.29, 4.41/62.7. Fuc: $\delta 4.90(1 \mathrm{H}, \mathrm{d}, 7.8) / 105.5 ; 4.27 / 71.4 ; 4.11 / 75.5 ; 4.06 / 72.6$; 
3.82/71.4; $1.62(3 \mathrm{H}, \mathrm{d}, 5.6) / 18.9$. Qui: $\delta 4.89(1 \mathrm{H}, \mathrm{d}, 7.8) / 99.3 ; 4.02 / 75.5 ; 4.14 / 76.1 ; 3.75 / 76.8$; 3.73/72.7; $1.62(3 \mathrm{H}, \mathrm{d}, 6.3) / 18.9$. GIc III: $\delta 6.09(1 \mathrm{H}, \mathrm{d}, 8.0) / 95.7 ; 4.02 / 76.0 ; 4.16 / 78.2 ; 4.13 / 71.3$; 3.97/79.1; 4.16, 4.46/62.4. Rha: $\delta 5.93(1 \mathrm{H}$, br s)/101.8; 5.18/70.6; 4.96/81.9; 4.52/79.1; 4.56/69.1; $1.81(3 \mathrm{H}, \mathrm{d}, 6.4) / 18.8$. GIc IV: $\delta 5.37(1 \mathrm{H}, \mathrm{d}, 7.7) / 105.9 ; 4.00 / 75.2 ; 4.14 / 77.3 ; 4.12 / 71.1$; 3.91/78.2; 4.16, 4.25/62.7. Araf: $\delta 6.30(1 \mathrm{H}$, br s)/111.0; 5.02/84.5; 4.83/78.1; 4.78/85.4; 4.16, 4.24/61.8.

(Overlapped proton NMR signals are reported without designated multiplicity).

\section{Conclusions}

This study unveiled the presence of two new triterpenoid saponins from the stem barks of A. zygia. In comparison with the previous isolated triterpenoid saponins from the roots of the same plant, they share the same structural features: they all have acacic acid as aglycon unit, oligosaccharide moieties at C-3 and C-28, and an acyl group at C-21, differing only by the nature, number, and the substitution pattern of the oligosaccharide moieties attached at C-3 and C-28, and by the length of the Monoterpene-quinovosyl moiety at C-21, which are all known as acacic acid-type saponins (AATS) (Lacaille-Dubois et al. 2011). A. zygia may therefore be considered as a potential rich source of this type of complex saponins. Nevertheless, further studies are necessary to support this conclusion, especially the search of this type of triterpenoid saponins from the leaves of this species.

\section{Acknowledgments}

The authors are also grateful to Mr Victor Nana of the National Herbarium of Cameroon (NHC) for the identification and collection of plant.

\section{Disclosure statement}

No potential conflict of interest was reported by the authors.

\section{Funding}

This work was supported by the Agence Universitaire de la Francophonie (AUF) [grant number DRACGL-2017-007] (Joséphine Ngo Mbing).

\section{References}

Abdel-Kader M, Hoch J, Berger JM, Evans R, Miller JS, Wisse JH, Mamber SW, Dalton JM, Kingston DG. 2001. Two bioactive saponins from Albizia subdimidiata from the Suriname rainforest. J Nat Prod. 64:536-539.

Cao S, Norris A, Miller J. S., Ratovoson F., Razafitsalama JS, Andriantsiferana R, Rasamison VE, TenDyke K, Suh T, Kingston DGl. 2007. Cytotoxic triterpenoid saponins of Albizia gummifera from the rain forest. J Nat Prod. 70:361-366.

Chaabi M, Chabert P, Vonthron-Sénécheau C, Weniger B, Ouattara M, Corstjens H, Sente I, Declercq L, Lobstein A. 2010. Acylated flavonol pentaglycosides from Baphia nitida leaves. Phytochem Lett. 3:70-74.

Haddad M, Miyamoto T, Laurens V, Lacaille-Dubois MA. 2003. Two new biologically active triterpenoidal saponins acylated with salicylic acid from Albizia adianthifolia. J Nat Prod. 66:372-377. 
Haddad M, Miyamoto T, Lacaille-Dubois MA. 2004. New triterpenoidal saponins acylated with monoterpenic acid from Albizia adianthifolia. Helv Chim Acta. 87:1228-1238.

Krief S, Thoison O, Sévenet T, Wrangham RW, Lavaud C. 2005. Triterpenoid saponin anthranilates from Albizia grandibracteata leaves ingested by primates in Uganda. J Nat Prod. 68:897-903.

Lacaille-Dubois MA, Pegnyemb DE, Noté OP, Mitaine-Offer AC. 2011. A review of acacic acid-type saponins from Leguminosae-Mimosoideae as potent cytotoxic and apoptosis inducing agents. Phytochem Rev. 10:565-584.

Liang H, Tong WY, Zhao YY, Cui JR, Tu GU. 2005. An antitumor compound julibroside $\mathrm{J}_{28}$ from Albizia julibrissin. Bioorg Med Chem Lett. 15:4493-4495.

Liu R, Ma S, Liu Y, Yu S, Chen X, Zhang J. 2010. Albizosides D and E, two new cytotoxic triterpene saponins from Albizia chinensis. Carbohydr Res. 345:1877-1881.

Noté OP, Mitaine-Offer AC, Miyamoto T, Paululat T, Mirjolet JF, Duchamp O, Pegnyemb DE, LacailleDubois MA. 2009. Cytotoxic acacic acid glycosides from the roots of Albizia coriaria. J Nat Prod. 72:1725-1730.

Noté OP, Chabert P, Pegnyemb DE, Weniger B, Lacaille-Dubois MA, Lobstein A. 2010. Structure elucidation of new acacic acid-type saponins from Albizia coriaria. Magn Reson Chem. 48:829-836.

Noté OP, Jihu D, Antheaume C, Zeniou M, Pegnyemb DE, Guillaume D, Chneiwess H, Kilhoffer MC, Lobstein A. 2015. Triterpenoid saponins from Albizia lebbeck (L.) Benth and their inhibitory effect on the survival of high grade human brain tumor cells. Carbohydr Res. 404:26-33.

Noté OP, Simo L, Mbing JN, Guillaume D, Aouazou SA, Muller CD, Pegnyemb DE, Lobstein A. 2016. Two new triterpenoid saponins from the roots of Albizia zygia (DC.) J.F. Macbr. Phytochem Lett. 18:128-135.

Zheng L, Zheng J, Zhao Y, Wang B, Wu L, Liang H. 2006. Three anti-tumor saponins from Albizia julibrissin. Bioorg Med Chem Lett. 16:276-2768.

Zheng L, Zheng J, Zhang Q, Wang B, Zhao Y, Wu L. 2010. Three new oleanane triterpenoid saponins acetylated with monoterpenoid acid from Albizia julibrissin. Fitoterapia. 81:859-863.

Zou K, Zhang QY, Wang B, Cui JR, Zhao YY, Zhang RY. 2010. Cytotoxic triterpernoid saponins acetylated with monoterpenoid acid from Albizia julibrissin. Helv Chim Acta. 93:2100-2106. 